\title{
Research on mediated suffering within social sciences: expert views on identifying a disciplinary home and research agenda
}

\section{Synopsis}

An emerging field of research within social sciences concerns itself with the issue of suffering. Following its growing (mediated) societal prevalence and impact in recent years, suffering has already spurred a rich and diverse body of work. Alongside its emergence within academia, questions arose about its disciplinary home and scope. Drawing on elite interviews with twelve leading scholars, this article positions the on-going research on media and suffering at the heart of social sciences and humanities as well as at the crossroads of different disciplines. This overall open view was reflected in discussions on the current and future scope of the research. Regarding future directions, empirical audience research is high on the academic agenda as are studies that look into the role of new media with regard to suffering. Other widely shared comments referred to a further opening up of the research in terms of methodological and disciplinary approaches.

Keywords: suffering, media, (inter)disciplinarity, elite interviews

\section{Author information}

Stijn Joye ( $\mathrm{PhD}$, Ghent University 2010) is an assistant professor at the Department of Communication Sciences (Ghent University, Belgium) where he is member of the Centre for Cinema and Media Studies (CIMS) and the Center for Journalism Studies (CJS). He was also a lecturer at Erasmus University Rotterdam (The Netherlands, 2010-2011) and a Visiting Fellow at London School of Economics and Political Science (UK, 2012). His areas of research and publication include international and foreign news, global news agencies and the representation of distant suffering.

Stijn.Joye@UGent.be

Korte Meer 7-11, 9000 Gent, Belgium 


\section{Introduction}

In his seminal work 'Risk Society: Towards a New Modernity', Beck (1992) assessed modern society as increasingly preoccupied with invisible, unpredictable and uncontrollable risks such as disasters, terrorism, poverty, pandemics and conflicts. These situations of risk are "global in their nature, scope, and potential impacts" (Cottle 2009b, 351) and appear to have increased in frequency and intensity over the last few years (Guha-Sapir et al. 2004, 13). Acknowledging the rise in (representations of) global suffering, Cottle (2009a, 70) argues that "[m]ediated global disasters demand increased attention from media researchers in the future, both empirically and theoretically." In recent years, social scientists have certainly picked up on the emerging presence and mediated manifestation of suffering within contemporary society. Scholars from different disciplines have been paying particular attention to the relationship between suffering and media. This increasing academic attention has resulted in a wide range of research foci, varying from disaster news coverage, representation of distant suffering, sociological concerns about risk society, media witnessing, and peace and conflict studies. In addition to this, new journal titles, high-profile book series and recently established sections at different international academic associations underline the growing and very diverse interest in the field and the professional scholarly preoccupation with it. However, this has led to a definitional vagueness of this emerging field that is seemingly in search of an identity. Acknowledging the diversity of research and the richness of the on-going academic debate, how, then, can we define the field in terms of scope, key concepts and research questions with regard to suffering and media? Can we mark out the disciplinary borders? And, most importantly, with respect to the value of interdisciplinary research, is there any need to do so? One of the prominent debates that will be addressed in this article is this tension between discipline and interdisciplinary research. The key issue explored here is the question about discipline: does the research on media and suffering constitute an established or emerging discipline or rather an interdisciplinary field of inquiry? Observing the interdisciplinary dialogues as well as charting the different strands of media and communication studies on suffering, a second objective of this article is to assess the current and future state of the research on mediated suffering, with a particular aim to identify future directions to move the research forward. For this purpose, we draw on a literature review and elite interviews with leading scholars in the field. The literature review is divided into two parts. First, we address suffering as an object of scholarly inquiry within the broad field of social sciences. Secondly, we give a general outline of the research on media and suffering.

\section{Suffering and the social sciences}

In this article we dwell on the definition of suffering by Kleinman, Das and Lock (1997, xi). They approach suffering as "an assemblage of human problems that have their origins and consequences in the devastating injuries that social force can inflict on human experience", including political, social, institutional and economic conditions that involve health, welfare, legal, moral and religious issues. This is a very broad definition, but it allows us to address the field in its full complexity as it reflects the variety of possible causes of human suffering. In addition, it does not limit the concept of suffering to the individual experience of pain, loss or psychological distress (Steeves and Kahn 1987), but opens it up to collective forms of suffering and manners of coping with it. Nonetheless, forms of social suffering also evoke individual lives and personal accounts, but they embed these in the broader social context (Kleinman et al. 1997, 
xxvii). In our interpretation of suffering, we further focus on acts of misfortune that are inflicted upon (a collectivity of) people. The causes or the results of suffering are often situated outside of human control or will of the sufferer; for example, (natural and technological) disasters, complex emergencies (domestic disturbances, armed conflicts) or conditions of deprivation and poverty. Furthermore, given the emphasis of the article on the relationship between media and suffering, we will focus on a particular type of suffering, which is distant suffering. Drawing on the work of Boltanski (1999), we hereby refer to the suffering of distant others that is presented through the media. This definition, thus, precipitates moral and political dilemmas for the spectator who, due to his remoteness, cannot directly intervene to stop the suffering.

Following this conceptualisation, it is evident why suffering has attracted the attention of the social sciences. Suffering appeals to the basic human emotions of care and empathy, and its mediation resonates with the ethics of public life, issues of morality and the nature of the society in which we live. The subject of suffering touches the very foundations of what being human is about and does this in two profoundly opposite ways, which we could divide along the lines of the act of suffering and the reaction to suffering in relation to the human condition. This dual relation between suffering and humanity is eloquently touched upon by Wilkinson $(2005,2)$ who argues that "[w]hilst with one voice we empathically denounce this experience [of suffering] as a desecration of our humanity, with another we declare it to have the potential to reveal us in our most sanctified form." On the one hand, the act of suffering deconstructs and violates the core of being human. Suffering here relates to the notion of vulnerability as an intrinsic aspect of human beings. Hannah Arendt argued that in the most extreme forms of suffering, we are even deprived of our humanity, as suffering "destroys our bodies, ruins our minds, and smashes our "spirit"" (cited in Wilkinson 2005, 1). On the other hand, suffering can bring out the very best in humans by disclosing and eliciting emotions of pity, empathy and compassion. Charity appeals, international relief aid, humanitarian organisations, telethons, volunteering, etc. are all exemplary of this line of thought on suffering and humanitarianism.

\section{Scholarly interest in suffering: a characterisation}

In terms of the scholarly attention to suffering and its historical development, a brief overview allows us to make some general statements about the area's key characteristics.

First, research on suffering displays a variety of disciplinary interests and contributions, mostly rooted within social sciences but also humanities. According to Kleinman, Das and Lock (1997, xxvi), the shift from a dominant medical perspective on suffering as individual pain or misfortune contingent on illness happened quite recently and was facilitated by the emerging conception of suffering as profoundly social instead of as individual. Defining suffering as fundamentally social opened the discussion to a variety of disciplines within the broad realm of social sciences and humanities. These disciplines have theorised and studied suffering from their particular scopes or interests: sociology, political science, economics, communication science, anthropology, theology, law and ethics, and all have contributed to our understanding of suffering, its causes and consequences. Moreover, due to the diverse realities and nature of human suffering, several scholars such as Kleinman (1988), Graubard (1996) and Wilkinson (2005) are opposed to constraining the debate on suffering to a single discipline of study and, therefore, strongly support the value of interdisciplinary study as exemplified in the literature on suffering. Having said that, we should be aware of or at least acknowledge what MacIntyre (1981/2007) has called 
the modern problem of incommensurability in academic research. Despite interdisciplinary dialogues, each discipline dwells on its own premises and standards, leading us to the question of whether the various disciplinary narratives on, conceptualisations of and meanings awarded to suffering do not diverge epistemologically even if all use the same word(s) and terminology. In other words, is suffering a common term of reference across all disciplines? And does this lead to a totalizing body of knowledge or only to different partial understandings of suffering? This does not question the value of interdisciplinary research on suffering as such, but it is an important element to take into account when discussing the (need for) disciplinary boundaries of research on media and suffering.

Secondly, within social sciences, it appears that disciplines are exploring suffering at very different paces. While theology and philosophy, for instance, have a long-standing tradition of debate on the subject of suffering, other disciplines such as sociology or communication science have only (re)discovered suffering since the 1980s and 1990s (Wilkinson 2005, 3). In addition, Wilkinson (2005, 4-6) discerns four particular fields of inquiry that spearhead the contemporary scholarly debate and preoccupation with suffering: medical anthropology, which looks into the socio-cultural components of experiencing suffering and pain; ethnography, which explores human suffering in a context of extreme social adversity and political atrocity; sociology, which, according to Wilkinson, is given the particular responsibility of developing a language and framework for understanding what the experience of suffering actually does to people and our humanity; and media studies in which the role of media and mediation is investigated in the formation of moral behaviour, social consciousness and humanitarian concern with suffering. The latter field of research will be the focus of the next section.

Thirdly, and resonating with the broad conceptualisation of suffering adopted in this article, the interdisciplinary academic debate on suffering and its emergence are shaped by a set of societal transformations in terms of political, social, cultural, religious, economic and technological developments that occurred over the past several decades. In a comprehensive effort, several scholars such as Giddens (1990), Beck (1992), Wilkinson (2005), and Pantti, Wahl-Jorgensen and Cottle (2012) have linked the increase in risks or threats to humanity and the widespread misery of our human condition to some key characteristics of industrialised societies and our modern times. Among others, they point to a secular "age of great social injustice, cultural poverty and moral anxiety" (Wilkinson 2005, 3), as well as to the processes of industrial civilisation and their implications. Pantti, Wahl-Jorgensen and Cottle $(2012,1)$ also refer to a powerful combination of several worldwide and interconnected processes such as "climate change, population growth, urban migration and increased resource scarcity." Other scholars have pointed to the intensified processes of and academic work on mediation since the 1990s as a catalyst for scholarly attention to suffering. Important issues were, among others, such aspects as televised witnessing of live unfolding disasters or terrorist attacks, the rise of 24/24 global television news channels, technological changes such as digital media, and a dominance of infotainment formats that focus on the spectacle of suffering. In other words, the world is increasingly watching the plight and misfortunes of distant others. This increased visibility urges us to (continue to) take on suffering as a timely issue of academic interest and labour. Furthermore, we can refer to the increasing instrumentalisation of the aid and development field (Chouliaraki 2012) and the dramatic rise in the number of NGOs over the last few decades (Kennedy 2009) which have also played a vital role in making human suffering more visible to audiences and putting it on the agenda of policy-makers as well as making it a disciplinary 
concern for scholars. In taking this view, Wright (2002) also points to the current development of a new culture of cosmopolitan altruism. Other explanatory factors could be related to an apparent quantitative or qualitative increase in suffering itself and its growing human, economic and political (destructive) impact. Wilkinson $(2005,7)$ adds that we should always expect a considerable interval of time before people are ready to grasp the extent and meaning of an atrocity and the ensuing suffering. He considers the recent upsurge of scholarly interest as a subsequent stage or development in the on-going struggle to understand and interpret the unprecedented amount of documented suffering that the world has encountered in the last three decades. Along these lines, he regards the increasing concern of social science with suffering as a "sign of the intensifying force of 'moral individualism' within [modern] society" (Wilkinson $2005,134)$ that serves to involve scholars in such pressing issues of suffering and humanity. The following part of the literature review takes a closer look at the research on media and suffering.

\section{Communication science and suffering}

Within the scope of this article, it is impossible to present a comprehensive overview in terms of individual projects, scholars and contributions from all the different disciplines. Therefore, we will mainly explore suffering in relation to media by presenting a brief historical overview and the major strands of research. The literature provides us with a number of arguments to support this rationale of studying suffering in relation to media.

First, this approach is premised on the general understanding of media as "sources of power as well as of meaning - mediated meanings can have powerful social consequences" (Jensen 2002, 273) such as raising public action or moral dispositions towards it - be it compassion, pity or irony - which the mediation of suffering problematizes (Chouliaraki 2006; 2012). In exercising their symbolic power, (news) media occupy a key position in social processes of for instance public understanding and political response (Cottle 2009a, 2). Echoing the notion of suffering as profoundly social, a study of the mediation of suffering and the accommodating discourses, therefore, involves several aspects of the social realm, which critical media research aims to expose. We can refer to the articulation of power imbalances through representations of suffering. Other examples are the role of media in forming social conscience and moral behaviour; the process of witnessing suffering in, by and through media; the commodification of charity; etc. A critical orientation to suffering and media, thus, implies a readiness to accept such a conception of mediated suffering as a representation and as a construction of social life (Schrøder 2002, 100).

Secondly, a media-centred perspective on suffering is also very relevant for other reasons. Several scholars have demonstrated that for most people living in the developed world, disasters and other causes of suffering such as complex emergencies are distant events with which they are only confronted through media and their mediation (Benthall 1993; Boltanski 1999; Franks 2008; Joye 2009). According to Kitch and Hume (2007), it is such mediated and, hence, indirect exposure to human suffering that for most people is their most common grief and death experience in modern culture. Related is the emerging "'mediated ethics of care', an invitation [inscribed in media] to recognise, better understand and care about the plight of others" (Cottle 2009a, 93). Given the current and foreseeable future dominant role of mediation with regard to the social experience of suffering, it could even be argued that communication science represents the disciplinary home of suffering. Acknowledging the high number of studies conducted within 
this field, few would even dispute this. Other indicators in that respect are conferences on mediated suffering, recently established sections on crisis communication within international academic networks such as IAMCR and ECREA, new journals such as 'Media, War and Conflict' and special journal issues on risk and crisis, and various interventions in the public debate. Nevertheless, it should be emphasised that the body of work on media and suffering remains very heterogeneous in terms of disciplinary perspectives. Henceforth, and linking up to the previous discussion on discipline and interdisciplinary research, we explicitly wish to keep the issue open for argument and debate. For now, we refer to the analysis of the interviews during which the topic is raised as well.

\section{Media and suffering: a wide field of research}

Given the wide range of aspects and perspectives, the following brief account does not claim to present an exhaustive overview of all the ways in which communication science might inform our understanding of suffering. By consequence, we will identify three main fields of scholarly inquiry.

A major strand of research investigates the process of producing ${ }^{1}$ images and narratives of suffering, generally against the backdrop of journalism studies. Theories and studies on news values or newsworthiness, gatekeeping, the work of foreign correspondents, etc. are very prominent, although the issue of suffering often appears to be of rather secondary importance or mainly serving as a case study. An interesting - interdisciplinary - subfield within journalism studies concerns the study of trauma of journalists that are covering scenes of misery and death (Rentschler, 2011). Other subjects of research are photojournalism and the moral issues involved with producing images of death, pain and suffering (Sontag 2003; Hanusch 2010; Zelizer 2010). Next to journalists, academia is increasingly paying attention to other producers of content such as the relief aid and charity sector. Scholars like Benthall (1993) and Cottle and Nolan (2007) have written influential pieces on the changing dynamics of the aid-media field with a focus on NGOs, while others have focused on celebrities who have become a key feature of contemporary humanitarian communication (Littler 2008; Chouliaraki 2012; Driessens et al. 2012).

Besides issues of production, a significant and expanding body of work has emerged relating to the content of mediated suffering. Different research topics can be identified in this regard: the repetitive use of visual and narrative stereotypes, the representation of pity and the 'othering' of the distant sufferer, articulations of power imbalances or hierarchies, the naturalisation and depoliticisation of suffering, discourses of emotion in news reports, etc. (see Benthall 1993; Moeller 1999; Chouliaraki 2006; Kitch and Hume 2007; Cottle 2009a; Pantti 2009; Joye 2010). A major contribution to this subfield was the research by Chouliaraki (2006) which moved the debate beyond the relatively abstract and generalizing statements about the representation of human suffering. She has identified a three-dimensional typology of news discourses and corresponding regimes of pity. Chouliaraki's work is leading an emerging field that critically observes and explains the discursive reproduction of symbolic inequalities and representational hierarchies in the mediation of distant suffering. This line of research has also highlighted the generally

\footnotetext{
${ }^{1}$ As the use of the term 'production' might stir some confusion, this overview of the field is restricted to the production of images and narratives on suffering in news media by journalists. This excludes, for instance, the strand of research on corporate crisis communication and risk or crisis management by authorities.
} 
understudied issue of the "underlying relational and ethical dimension embedded within televised scenes of suffering" (Cottle 2009a, 145).

A third dimension of scholarly interest concerns the matter of audience consumption and reception of suffering in, by and through the media. Research topics include the different categories of emotional commitment, moral response and dispositions of the audience (Höijer 2004) with central - although controversial - theoretical concepts such as compassion fatigue (Moeller 1999) and states of denial (Cohen 2001); the process of media witnessing (Frosh and Pinchevski 2011); the notion of mediatised rituals (Cottle 2006) and, in particular, mourning rituals (Pantti and Sumiala 2009); and the role of media in the construction of a mediated cosmopolitan space in which people care for the suffering of a distant other (Tester 2001; Silverstone 2007). It goes without saying that the notion of suffering as fundamentally social is very central to this line of research. Another key characteristic is the deep distinction that needs to be drawn between the theoretical and the empirical research done in this area of study. The former appears to have a longer tradition, originating in sociological accounts on the position of the audience with regard to human suffering. In contrast to these rich theoretical insights, Kyriakidou $(2011,17)$ and others refer to the absence "of [a] considerable amount of empirical work investigating and supporting the relevant theoretical arguments." Höijer (2004) and Wilkinson (2005) have argued before that there are few empirical studies of audiences' reactions to and interpretations of mediated suffering. Likewise, it seems that in terms of analyses of audience reception and response to suffering, the field is biased towards a negative appraisal and tends to neglect or minimise the media's potential to cultivate compassion or pity. Therefore, Cottle $(2009 a, 134)$ points "to the need for closer empirical engagement, refined concepts and further analytical distinctions" in the field of audience research related to suffering.

In addition to this outline and the overarching theme about discipline and interdisciplinary research, it is imperative to recognise mediated suffering, its experience and the social, cultural and institutional developments that it brings about as a distinctively new process (Wilkinson 2005, 146), henceforth acknowledging the scholarly work that lies ahead with regard to the refined concepts, theoretical framework and empirical analysis of suffering and media. Accordingly, one of the objectives of the interviews is to set out a future research agenda related to scholarly studies on media and suffering.

\section{Methodology}

In 2012, a series of semi-structured in-depth interviews was conducted with twelve internationally renowned scholars who are experts regarding the study of media and suffering. The topic-list addressed a number of issues that were derived from the literature review as well as dealt with broader reflections on the state and nature of the field. All conversations were recorded and then transcribed verbatim. Due to practical issues, interviews via e-mail were conducted with three scholars in addition to the nine face-to-face interviews in person or via Skype. On average, the face-to-face interviews lasted about 39 minutes, and the transcripts were analysed using qualitative content analysis techniques in line with the method of thematic coding (Jensen 2002, 247; Wester and Peters 2004, 83-103). Accordingly, statements of the interviewees were identified, compared, contrasted and subsequently clustered into two particular categories of data in relation to the broader context and objectives of this study: the disciplinary nature of the field and the future directions of research. 
As our initial sample of interviewees was inspired by the diversity of work conducted within the broad framework of media and suffering, scholars representing different disciplines of social sciences were selected such as media and communication science, sociology and anthropology. Another criterion for the selection of the respondents was their seminal work and publications on the topic of representation of suffering, henceforth stressing the idea of elite or expert interviews (Gogner et al. 2005). Furthermore, the interview sample was to a large extent determined by pragmatic considerations in terms of time, resources and spatial restrictions. Table 1 gives, with kind permission, an overview of the respondents, their positions and affiliation at the time of the interview, the date and the interview setting.

\begin{tabular}{|c|c|c|c|}
\hline Interviewee & Position and affiliation & Date of interview & Setting \\
\hline Jonathan Benthall & $\begin{array}{c}\text { Honorary Research Fellow, } \\
\text { Department of Anthropology, } \\
\text { University College London } \\
\text { (UK) }\end{array}$ & $16 / 02 / 2012$ & In person \\
\hline David Campbell & $\begin{array}{l}\text { Independent scholar, Honorary } \\
\text { Professor of Geography at } \\
\text { Durham University (UK) and } \\
\text { Honorary Professor in the } \\
\text { School of Political Science and } \\
\text { International Studies at the } \\
\text { University of Queensland } \\
\text { (Australia) }\end{array}$ & $16 / 03 / 2012$ & E-mail \\
\hline Lilie Chouliaraki & $\begin{array}{l}\text { Professor of Media and } \\
\text { Communications, London } \\
\text { School of Economics and } \\
\text { Political Science (UK) }\end{array}$ & $27 / 02 / 2012$ & In person \\
\hline Simon Cottle & $\begin{array}{l}\text { Professor of Media and } \\
\text { Communications, Cardiff } \\
\text { University (Wales) }\end{array}$ & 07/03/2012 & In person \\
\hline Suzanne Franks & $\begin{array}{l}\text { Professor of Journalism, City } \\
\text { University London (UK) }\end{array}$ & 29/03/2012 & In person \\
\hline Paul Frosh & $\begin{array}{l}\text { Professor of Communications } \\
\text { and Journalism, The Hebrew } \\
\text { University of Jerusalem (Israel) }\end{array}$ & $11 / 03 / 2012$ & E-mail \\
\hline Folker Hanusch & $\begin{array}{l}\text { Senior Lecturer in Journalism, } \\
\text { University of the Sunshine Coast } \\
\text { (Australia) }\end{array}$ & $22 / 03 / 2012$ & Skype \\
\hline Susan Moeller & $\begin{array}{c}\text { Professor of Media and } \\
\text { International Affairs, University } \\
\text { of Maryland (USA) }\end{array}$ & $20 / 03 / 2012$ & Skype $^{2}$ \\
\hline Shani Orgad & $\begin{array}{l}\text { Senior Lecturer in Media and } \\
\text { Communications, London }\end{array}$ & $22 / 03 / 2012$ & In person \\
\hline
\end{tabular}

\footnotetext{
${ }^{2}$ Due to technical problems, the interview only addressed the first set of questions on the nature of the field.
} 


\begin{tabular}{|c|c|c|c|}
\hline & $\begin{array}{c}\text { School of Economics and } \\
\text { Political Science (UK) }\end{array}$ & E-mail \\
\hline Mervi Pantti & $\begin{array}{c}\text { Associate Professor, Department } \\
\text { of Social Sciences, University of } \\
\text { Helsinki (Finland) }\end{array}$ & $30 / 03 / 2012$ & In person \\
\hline Keith Tester & $\begin{array}{c}\text { Professor of Sociology, The } \\
\text { University of Hull (UK) }\end{array}$ & $14 / 02 / 2012$ & In person \\
\hline Karin Wahl-Jorgensen & $\begin{array}{c}\text { Professor at Cardiff School of } \\
\text { Journalism, Media and Cultural } \\
\text { Studies, Cardiff University } \\
\text { (Wales) }\end{array}$ & $07 / 03 / 2012$ \\
\hline
\end{tabular}

\section{Results and discussion}

Although the interviews considered a wider range of topics, this article will highlight two key issues about the research on media and suffering that emerged from the thematic analysis of the interviews: the nature of the field and the future research agenda.

\subsection{The nature of the field}

\section{Between disciplinary borders and interdisciplinary dialogues}

The literature review demonstrates the emerging nature of the research on media and suffering, henceforth exposing an area of study looking for more theoretical development and empirical exploration. Such general observation also raises questions about the position and status of this line of research within the broader framework of social sciences. Does it constitute an established or a rather emerging independent discipline? Is it, on the contrary, subsumed by a broader strand of research and can we, thus, discern a disciplinary home? Alternatively, should we conceive it as an interdisciplinary field?

With no exception, our interviewees are reluctant to label the research on the relationship between media and suffering as an independent discipline, nor did they consider it to be a subfield of one particular discipline such as communication science or sociology. All value the interdisciplinary character of the crosscutting work conducted in this area of research, and some scholars such as Lilie Chouliaraki and Keith Tester suggested to approach it as a site of common concern, a constellation or nexus of people who are all working and writing on the same topic ${ }^{3}$ from different backgrounds by drawing on different theoretical strands. In discussing this issue, a broad range of disciplines was identified such as media and communication science, sociology, anthropology, psychology, philosophy, political science and law. Echoing findings from the literature review, others refer to the wide scope of topics that all reside under the broad label of 'suffering' as well as to its key social nature and its status as a universal human experience, both demanding an interdisciplinary approach and openness to all social sciences and humanities. By implication, Paul Frosh, Simon Cottle and Chouliaraki argue that being named as a distinct 'field'

\footnotetext{
${ }^{3}$ Shani Orgad states that the common or shared topic of suffering is - as such - not sufficient to think of it as an independent discipline due to the rich diversity of backgrounds, methodological approaches and motivations to study it.
} 
or 'discipline' would not benefit the research. Instead, it would prove to be counterproductive in terms of losing the input of various disciplines and vantage points. There was deep concern over seriously delimiting the academic work in its scope when raising borders or proceeding with a form of gatekeeping. Another element of caution to take into account when labelling it as a discipline is what Tester refers to as the process of naturalisation: "If we have something called 'suffering studies', we would be naturalizing suffering and accepting a world in which suffering occurs. Suffering would become defining of what it means to be human." Particularly in the case of suffering incited by conflicts or other man-made events of misfortune and atrocity, Tester warns for implicit acceptance and validation of such events when naturalizing the suffering. A final point hints at a broader epistemological discussion of how to define a discipline? Karin Wahl-Jorgensen and Folker Hanusch reflected on this issue and wondered whether this would mean that researchers share a particular view and critical mass. In Wahl-Jorgensen's opinion, the research on media and suffering hence represents an emerging interdisciplinary area of research rather than a discipline as such given that studies relating to suffering and media are "quite diverse, spread out over a long period of time and represent a variety of different methodological approaches."

Despite the overall shared plea for interdisciplinarity, some critical comments are uttered as well. Firstly, Chouliaraki points out that looking beyond the confines of one's own discipline is not an easy task to accomplish, as it means moving out of your comfort zone, challenging yourself and confronting new and possibly contradicting interpretations of what you have taken for granted. This is, at the same time, a situation of discomfort and agitation as well as one of intellectual satisfaction and richness, although the latter requires an open attitude and willingness to question oneself. The issue of disciplinary anchoring vis-à-vis interdisciplinary exchanges thus forces scholars to reflect on one's own position towards other scholars and disciplines as well as on the value of scholarly work that crosses disciplinary borders or, perhaps more important, fails to do so. Given the multifaceted issue of suffering, such questions are central in the daily praxis of scholars who are working in this broad field. Tester picks up on this position of discomfort by calling attention to a tendency of many scholars to stay within their disciplinary home and henceforth orient their dialogue to those who know the terms of reference with which they are familiar. To some degree, disciplinarity would hence avert the earlier-discussed problem of incommensurability (see section 2). Although in favour of an interdisciplinary approach, Cottle also sees possible value in delineating some disciplinary boundaries, as this might result in a more rigorous and in-depth research approach as well as a clustering of expertise and knowledge.

Secondly, our interviewees refer to some unrealistic expectations that are linked to interdisciplinary work, which is often believed to fully achieve a totalizing knowledge of suffering. Instead, we need to acknowledge that as individual scholars with particular disciplinary backgrounds, we are capable of generating only a partial understanding of suffering as a fundamental human experience. Mervi Pantti adds an important remark to this discussion as she urges scholars from different disciplines to engage in a far more widespread "sharing of knowledge and thereby advancing theory rather than that we all keep on inventing the same wheel in our own disciplinary homes." Shani Orgad also criticises the insular and isolated discussions while Chouliaraki and Cottle commented on a tendency within each separate research tradition "to continue to sort out concepts as if the Holy Grail is to be reached", leading to a degree of conceptual indistinctiveness (cf. infra). In order to achieve a deeper understanding of suffering, we need to, thus, establish more interdisciplinary dialogue and exchange of knowledge. 
In other words, researchers operating in an intrinsic interdisciplinary field such as suffering are required to share knowledge, to be open to possible aberrant definitions and to accept a certain indispensable degree of contestation of terminology which echoes the above-mentioned discussion on a totalizing knowledge of suffering.

Thirdly, our respondents point to some of the key ways in which disciplines function within academic institutions as they recognise the institutional perils or challenges of not having a single disciplinary home with regard to grant applications or even job opportunities for young scholars who are working in an area as expansive as media and suffering. The latter point was most explicitly raised by Susan Moeller, who hints at the competitive academic system in the U.S.A. and the current sway of tenure contracts, which more often than not require a strong positioning within a distinct field or discipline. Related to this pragmatic value of naming it a discipline is what Hanusch has referred to as the leading policy and increasing pressure of review boards or indexes to label and categorise research into clear-cut or insular fields of interest and scholarly work. In this respect, the findings of the interviews and the literature review contribute to a broader consideration or even reappraisal of the value and relevance of interdisciplinary research within the wider academic landscape and related policy field.

To sum up the discussion on the pros and cons of establishing disciplinary borders, Tester eloquently summarises the main driving idea that this site of study should be "delimited by its gates rather than by the high fences it builds to keep others out." It is fair to say that all of our interviewees are definitely in favour of the interdisciplinary approach to suffering while simultaneously being attentive to some of the drawbacks that such an approach may cause. A final remark in this regard, however, refers to comments by several scholars such as Cottle, Franks and Hanusch, who do not wish to exclude the possibility that the study of suffering (and its relationship with media) might eventually develop into a discipline of its own, one that is informed and enriched by various theoretical strands and insights.

\section{Rise in scholarly interest}

Alongside the main issue of discipline and interdisciplinary research, the scholars who were interviewed were asked to reflect on possible explanations for the current rise of interest in the topic of mediated suffering and the increasing scholarly preoccupation within social sciences with the issue of suffering. Before doing so, Cottle and Orgad made a vital qualification when stressing the historical development of research on suffering and media, as this dimension is often neglected in the debates. In their view, there has always been an academic interest in the topic, but nowadays it is more articulated and part of a new momentum. The recent revival in scholarly attention to mediated suffering has been attributed to a diverse number of explanations, but we were able to discern four commonly uttered determinants, which, to a large extent, overlap with the arguments that we have identified in the literature review.

Firstly, the global nature and prevalence of risk and suffering-related events in general that affect a growing number of people are believed to be essential factors in stimulating academic research on suffering. Wahl-Jorgensen and Cottle, for instance, detect an increasing coming to terms within social sciences with the realities of global suffering. In this respect, Tester makes an important point. As (Western) academics, most of us do not know what it is like to suffer. Scholarly work on suffering is, thus, conducted at the level of the meaning of suffering, taking a 
modest stance towards the sufferers when it comes to the experience of suffering. Secondly, and related to the former, Frosh refers to its status of being "immanently and permanently on display through ubiquitous media." People are thus experiencing a greater capacity to recognise suffering and respond to it. Campbell, Cottle and Pantti also refer to these vital technological changes, which, according to them, have resulted in more scholarly attention to issues of mediation, representation and performance. Thirdly, this pervasive media representation of the other's suffering poses significant moral claims upon the audience, which, at the time, challenged traditional theories of mediation to investigate this dimension of audience practices. The link with a globalisation of the public sphere and a broader tendency towards cosmopolitanism is raised several times in this context, as is the relationship between media and the emerging humanitarian sector. Moeller, Chouliaraki and Orgad relate these elements to a general rise of humanitarianism and an accompanying scholarly acknowledgement of this, which has led, they assert, to a moral turn in social sciences and academic debates. Wahl-Jorgensen prefers to define it as an affective turn due to the increasing role of emotions in public and media discourses. Finally, scholars such as Campbell, Pantti and Tester refer to wider intellectual changes within social sciences and humanities as well, including new approaches, conceptualisations and shifts in focus and research topics.

\section{Western field?}

Further discussions briefly addressed the Western and even Eurocentric nature of the field as several interviewees point towards the absence of non-Western scholars studying questions of media and suffering. Wahl-Jorgensen, Tester and Orgad refer to global power relations and the possibility of imperialism to explain this, implying the positioning of the researcher's Western standpoint as comfortable or "privileged" and enabling one to remotely study such an issue as suffering. Having said that, Chouliaraki stresses that acknowledging this Western nature of the field cannot be misinterpreted as an absence of a critical stance towards Western media and their representation of suffering. For some respondents such as Frosh and Hanusch, this characterisation of the field is, however, not surprising given that communication science, along with much of the humanities and social sciences in general, are predominantly Western and Eurocentric. Echoing the idea of incommensurability (see section 2), Campbell states that it is only possible to have similar notions of, for instance, distant suffering within that particular (geographical) domain. Beyond it, that should not be assumed and would have to be researched. This is an objective that many of our respondents highlight as research on suffering and humanitarian discourses from and in the so-called global South would provide the on-going debate with significant empirical input and theoretical challenges. In the following section on future directions, we will come back to this point.

\subsection{Setting out a future research agenda}

The literature review revealed the recent nature of the research on media and suffering, simultaneously exposing a wide range of future research lines. Our respondents were asked to reflect on what is currently lacking more theoretical and empirical study.

Remarkably, almost all scholars mentioned the need for more empirical work on audiences as their first point of future interest. As became evident in the literature study, most scholarly work has focused on the textual dimension and there are only vague or sporadic references to how 
these texts affect audiences. In the words of Wahl-Jorgensen, our "understanding of audience reactions to and their perception of suffering is largely based on assumptions, not on empirical evidence." Following this, Wahl-Jorgensen calls for research that conceptualises and investigates a more differentiated understanding of emotional expressions, instead of the predominantly negative interpretation that led to theories on compassion fatigue and states of denial. This links up to a broader criticism of many respondents that the thesis of compassion fatigue suffers from a tendency to generalise and is, therefore, demonstrating neglect of the rather discrete forms of audience reactions to suffering. Criticism further addresses the lack of detailed empirical evidence and conceptual clarity as compassion fatigue appears to cover everything alongside the implied assumption that compassion is a "natural" feeling (Pantti, Tester) and a universal phenomenon (Cottle). A number of scholars such as Campbell, Franks and Pantti would welcome more audience research because of the transformation of media witnessing in the digital era. According to Campbell, the rise of social media would, however, demand a reconceptualisation of media and the notion of audience as vital starting points of any audience study as these are "outdated and limited by emphasis on broadcast rather than engagement."

This brings us to our second most-cited topic, which is a widely shared call for more intensified theoretical and empirical studies of new media and the role they are playing with regard to witnessing suffering. Frosh foresees more work on the relationship of new media technologies with forms of affect, agency and moral response. To make this more tangible, Chouliaraki and Cottle wonder to what extent new communication technologies empower people in disaster situations to act on their suffering. In relation to the media and the use of social media in crisis events, Wahl-Jorgensen and Benthall, furthermore, point to the need for more research on the changing modes and practices of production.

A third cluster of future directions is closely related to the findings from the literature review and stems from a sense of dissatisfaction with the current state of research vis-à-vis the respondents own background and expertise. Several scholars commented on a degree of conceptual indistinctiveness and a need for more theoretical and conceptual work in this field. The need for some measure of conceptual hygiene was mainly directed towards the discussion on audiences' reactions to suffering. For instance, all too often terms such as pity, compassion and empathy are used interchangeably while they are related to different disciplinary homes and refer to very distinct types of audience involvement and reaction. Wahl-Jorgensen further addressed a bias in the current research to focus mainly on major or exceptional news events, hence missing the everyday routines and the smaller issues such as unemployment or the loss of a pet. Likewise, the suggestion to investigate other genres and formats of media, besides news media, can also be seen in this light. Hanusch mentioned a closer look at the imaginary and visual culture of suffering. In the view of Tester, the field could also be advanced by approaching suffering as a social phenomenon and subsequently observing the producers and consumers of mediated suffering in a broader social context. In other words, a less media-centric and more sociological approach is being argued for here. Benthall, on the other hand, would welcome more work on a political economy of the media-disasters relationship, whereby northwards exported representations of suffering are studied as consumables, which are subsequently reciprocated by aid flows to the South. Finally, Chouliaraki and Tester find the historical perspective underdeveloped in much of the current research. 
Fourthly, in terms of applied methodologies, Benthall and Cottle argue for more ethnographic fieldwork. For instance, they refer to a lack of knowledge on the work and daily practices of mainly NGOs, but also of journalists in areas and populations that were directly affected by a disaster or that experienced great suffering. Another issue is the slumbering tendency towards methodological nationalism - manifesting itself in a plethora of national case studies - which ignores the global nature of suffering and the changing geopolitical situation. Hanusch and Franks would welcome more international comparative research on the theme of mediated suffering. Related to this is a plea for more research on non-Western cases and contexts by, preferably, non-Western academics or what Orgad calls a de-Westernised research area.

A final point of debate brings us back to the topic of discipline and interdisciplinary research. Several scholars such as Chouliaraki, Cottle and Orgad foresee future advances in enhancing the dialogue and exchange between the different disciplines that take up the topic of suffering. True to its interdisciplinary nature, suffering will continue to attract contributions from various backgrounds and our interviewees thus value an opening up to even more disciplines within social sciences and humanities such as marketing related to relief aid and humanitarian appeals (Franks), social psychology (Cottle), development studies (Benthall), history and political philosophy (Chouliaraki), moral philosophy (Orgad), political science and even architecture (Wahl-Jorgensen). This final point also reflects the earlier-mentioned perception of the field of suffering as an inclusive rather than an exclusive area of research.

\section{Conclusion}

In recent years, and informed by its widespread societal presence and impact, the issue of suffering has intrigued an increasing number of scholars and has already spurred a rich body of work, reflecting an astonishing richness in terms of approaches, theoretical perspectives and topics of study. Many have recognised the research on media and suffering as a legitimate, timely and necessary field of study, but alongside its emergence within academia questions arose on its disciplinary home and nature. This article primarily addresses the tension between discipline and interdisciplinary research: does the research on media and suffering constitute an established or emerging discipline or an interdisciplinary field. Or, is it embedded in a broader strand of research and can we thus discern a disciplinary home?

Drawing on twelve semi-structured interviews with leading scholars, a strong reluctance towards conceiving the on-going research as a discipline on its own was identified. All scholars prefer to look at it as a constellation of people, working from different perspectives and backgrounds, but all interested in the same topic. In other words, an area of research that is defined by an inherent interdisciplinary coming together of research interests, expertise and people, characterised by its gates rather than by its borders. Advantages and disadvantages of such conceptualisation were discussed, but the social nature of suffering and its status as a fundamentally human experience informed the debates. This has resulted in a positioning of the research on media and suffering at the heart of social sciences and humanities, as well as at the crossroads of different disciplines and with no urge to restrict or delimit the scope of research. This open view was also reflected in the discussion on the characteristics of the on-going research and the future research agenda. Regarding the latter, the scholars pointed towards a number of directions to move the research forward. Empirical audience research is especially high on the academic agenda as are studies 
that look into the role of new media. Other widely shared comments included a further opening up of the research in terms of new methodological and other disciplinary approaches.

Following the debate on disciplinary accounts, we acknowledge the study of media and suffering as an open and interdisciplinary area of research that underwrites and reflects its object's multilayered and intrinsic human and social nature. Attending to the human experience of suffering and its immanently and permanently display through ubiquitous media nowadays requires a concerted scholarly effort. We argue that such an effort needs to be informed and supported by various disciplines of social sciences in order to grasp the full range of theoretical, analytical and

moral issues at stake here. In this respect, this article makes a particular plea for further interdisciplinary dialogue and debate by social sciences and humanities to come to a more comprehensive understanding of suffering and its mediated experience.

\section{References}

Beck, Ulrich. 1992. Risk society. Towards a new modernity. London: Sage.

Benthall, Jonathan. 1993. Disasters, relief and the media. London: I.B. Tauris.

Benthall, Jonathan. 2007. Islamic charities, faith-based organizations and the international aid system. In Islamic charities, ed. Jon Alterman and Karin van Hippel, 1-15. Washington: Center for Strategic and International Studies.

Boltanski, Luc. 1999. Distant suffering. Cambridge: Cambridge University Press.

Chouliaraki, Lilie. 2006. The spectatorship of suffering. London: Sage.

Chouliaraki, Lilie. 2008. The media as moral education. Media, Culture \& Society 30, no 6: 83152.

Chouliaraki, Lilie. 2012. The ironic spectator. Solidarity in the age of post-humanitarianism. Cambridge: Polity.

Cohen, Stanley. 2001. States of denial. Cambridge: Polity.

Cottle, Simon. 2006. Mediatized rituals: beyond manufacturing consent. Media, Culture \& Society 28, no 3: 411-32.

Cottle, Simon. 2009a. Global crisis reporting. Journalism in the global age. Berkshire: Open University Press.

Cottle, Simon. 2009b. Journalism and globalization. In The handbook of journalism studies, ed. Karin Wahl-Jorgensen and Thomas Hanitzsch, 341-56. New York: Routledge.

Cottle, Simon, and David Nolan. 2007. Global humanitarianism and the changing aid-media field. Journalism Studies 8, no 6: 862-78.

Driessens, Olivier, Stijn Joye and Daniël Biltereyst. 2012. The X-factor of charity: A critical analysis of celebrities' involvement in the 2010 Flemish and Dutch Haiti relief shows. Media, Culture \& Society 34, no 6: 709-25.

Franks, Suzanne. 2008. Getting into bed with charity. British Journalism Review 19, no 3: 27-32.

Frosh, Paul, and Amit Pinchevski, Ed. 2011. Media witnessing. Testimony in the age of mass communication. Basingstoke: Palgrave Macmillan.

Giddens, Anthony. 1990. Consequences of modernity. Cambridge: Polity Press.

Gogner, Alexander, Beate Littig and Wolfgang Menz, Ed. 2005. Das Experten-interview. Theorie, Methode, Anwendung [The expert interview. Theory, methodology and practice]. Wiesbaden: Verlag für Sozialwissenschaften.

Graubard, Stephen. R. 1996. Preface to the issue 'Social Suffering'. Daedalus 125, no 1: v-X. 
Guha-Sapir, Debarati., David Hargitt and Philippe Hoyois. 2004. Thirty years of natural disasters 1974-2003: The numbers. Brussels: CRED.

Hanusch, Folker. 2010. Representing death in the news. Journalism, media and mortality. Basingstoke: Palgrave Macmillan.

Höijer, Brigitta. 2004. The discourse of global compassion. Media, Culture \& Society 26, no 4: 513-31.

Jensen, Klaus Bruhn. 2002. A handbook of media and communication research: Qualitative and quantitative methodologies. London: Routledge.

Joye, Stijn. 2009. The hierarchy of global suffering: A critical discourse analysis of television news reporting on foreign natural disasters. The Journal of International Communication 15, no 2: 45-61.

Joye, Stijn. 2010 News discourses on distant suffering: a Critical Discourse Analysis of the 2003 SARS outbreak. Discourse \& Society 21, no 5: 586-601.

Kennedy, Denis. 2009. Selling the distant other: Humanitarianism and Imagery - Ethical Dilemmas of Humanitarian Action. The Journal of Humanitarian Assistance 411 (February 28), http://sites.tufts.edu/jha/archives/411 (23/8/2012).

Kitch, Carolyn, and Janice Hume. 2007. Journalism in a culture of grief. New York: Routledge

Kleinman, Arthur. 1988. The illness narratives. Suffering, healing and the human condition. New York: Basic Books.

Kleinman, Arthur, Veena Das and Margaret Lock, Ed. 1997. Social suffering. Berkeley: University of California Press.

Kyriakidou, M. 2011. Watching the pain of others: Audience discourses of distant suffering in Greece. PhD diss., London School of Economics and Political Science.

Littler, Jo. 2008. 'I feel your pain': cosmopolitan charity and the public fashioning of the celebrity soul. Social Semiotics 18, no 2: 237-51.

MacIntyre, Alasdair. 1981/2007. After virtue. A study in moral theory. Notre Dame, Indiana: University of Notre Dame Press.

Moeller, Susan D. 1999. Compassion fatigue. How the media sell disease, famine, war and death. London: Routledge.

Pantti, Mervi. 2009. Wave of compassion. Nationalist Sentiments and Cosmopolitan Sensibilities in the Finnish Press Coverage of the Tsunami Disaster. In After the tsunami, ed. Ullamaija Kivikuru and Lars Nord, 83-106. Göteborg: Nordicom.

Pantti, Mervi, and Johanna Sumiala. 2009. Till death do us join: media, mourning rituals and the sacred centre of the society. Media, Culture \& Society 31, no 1: 119-35.

Pantti, Mervi, Karin Wahl-Jorgensen and Simon Cottle. 2012. Disasters and the media. New York: Peter Lang Publishing.

Rentschler, Carrie. 2011. From danger to trauma. In Media witnessing. Testimony in the age of mass communication, ed. Paul Frosh and Amit Pinchevski, 152-75. Basingstoke: Palgrave Macmillan.

Schrøder, Kim .C. 2002. Discourses of fact. In A handbook of media and communication research: Qualitative and quantitative methodologies, ed. Klaus Bruhn Jensen, 98-116. London: Sage

Silverstone, Roger. 2007. Media and morality: On the rise of the Mediapolis. Cambridge: Polity Press.

Sontag, Susan. 2003. Regarding the pain of others. New York: Farrar, Straus and Giroux.

Steeves, Richard H., and David Kahn. 1987. Experience of meaning in suffering. Journal of Nursing Scholarship 19, no 3: 114-6. 
Tester, Keith. 2001. Compassion, morality and the media. Buckingham: Open University Press. Wester, Fred, and Vincent Peters. 2004. Kwalitatieve analyse. [Qualitative analysis]. Bussum: Uitgeverij Coutinho.

Wilkinson, Iain. 2005. Suffering: A sociological introduction. Cambridge: Polity Press.

Wright, Karen. 2002. Generosity versus altruism: philanthropy and charity in the US and UK. Civil Society Working Paper series 17. London: Centre for Civil Society, LSE.

Zelizer, Barbie. 2010. About to die: How news images move the public. Oxford: Oxford University Press. 